\title{
The Effect of Single Leg and Double Leg Bounding Exercise Programme (BEP) on Increasing Physical Abilities, Strength, and Agility
}

\author{
Mohammad Zaim Zen ${ }^{1}$, Hari Setijono ${ }^{2}$, Nining Widyah Kusnanik ${ }^{3}$ \\ ${ }^{1}$ Postgraduate Program in Sports Science, Universitas Negeri Surabaya, Indonesia \\ 2,3 Department of Sports Coaching, Faculty of Sport Sciences, Universitas Negeri Surabaya, Indonesia \\ Email: mohammadzen16070946011@mhs.unesa.ac.id
}

\begin{abstract}
:
The purpose of this study was to investigate and examine the effect of using the Single Leg and Double Leg Bounding Exercise Program (BEP) on the Improvement of Physical Strength and Agility. The subjects of this study were physical education students class 2017 STKIP PGRI Jombang with 42 people. This type of research is quantitative with a quasi-experimental technique (quasi-experimental). Sampling used the solvin formula and purposive sampling technique. The process of collecting data for the initial and final tests used a leg dynamometer test to determine leg muscle strength and the side-step test for agility. The study results on normality and homogeneity tests showed normal and homogeneous data results with a significance value above 0.05 . The mean difference test was carried out using the paired test and the Manova test. The method of increasing the ability of strength and agility has a significant improvement with the two experimental methods.
\end{abstract}

Keywords:

single leg and double leg bounding exercise program; agility; strength

\section{Introduction}

An athlete in the modern era is required to have excellent physical performance. An athlete must constantly improve his physique. By developing the world of sports achievements, the developments related to the science of coaching in sports can also be ascertained to be growing. This has resulted in several sports experts, especially in the physical field, always innovating and conducting various studies to obtain scientific evidence about the proper method to improve athletes' physical performance.

Modern sports do require every athlete to have good physical performance. Physical performance that works optimally will make it easier for someone to make movements according to what they want when doing sports. If the physical performance is not good, it will be directly related to the decline in athletes in the field. This will certainly hinder the athlete's achievement.

In the modern world, fitness or physical condition experts try to take advantage of new scientific methods to prepare professional athletes in various national and international competitions. Therefore, the proper use of the best training methods is the most important basis that experienced professionals in the professional field must carry out. Currently, there is a wide variety of scientific research on athletes, competitions, and physical training. In this case, one of the most effective ways to increase athletes' strength and muscle endurance, speed, and power is plyometric training (Aghababaei, 2010). 
An athlete or athlete always has an exercise program that is structured systematically and in accordance with the ultimate goal of the exercise itself. Exercise, in principle, is a process of change for the better, namely to improve the physical quality, the functional ability of body equipment, and the psychological quality of athletes (Blumenstein, 2007). If physical exercise is carried out correctly, it can be ascertained that the results of the exercise undertaken will improve an athlete's physical performance. The concept of primary health care as a Gatekeeper was developed by the Johns Hopkins University Primary Care Center, covering 4 main domains namely first contact care (continuity function), continuity care, coordination care and comprehensiveness care (comprehensiveness care) service) (Novita et al, 2020). Mu'rifah in Hasibuan et al (2019) stated about personal health, namely that someone will try to maintain andincrease their own level of health in order to achieve peace of life and have the best workforce.

According to Stone (2007), training is a process in which athletes prepare their physical condition to be improved to the maximum. The processes at the time of training depending on the needs of each athlete, the specificity of the athlete's needs makes it mandatory for coaches to understand the principles of development in training. Physical exercise or sport has been known as a way to maintain and improve physical fitness. One of the most common physical exercises is strength training using weights. In simple terms, strength is defined as the ability to apply force. This power may be related to mechanical characteristics and human skills. Strength can also be interpreted as the ability of muscle nerves to overcome the resistance that coming from outside and from within (Acep, 2010: 6). While strength training, according to Sukadiyanto that "strength must be increased as the underlying foundation in other biomotor components. Muscle strength is the ability of the neuromuscular system to produce force or force (Chandler and Brown, 2008: 279). Powerful muscle contractions in response to dynamic loading or rapid stretching of the muscles involved. Based on the opinion, strength is defined as the ability or quality of the muscles in contracting to handle the load. The load may come from both the burden of the body itself and the burden of the body plus the outside.

Agility is a biomotor component found in various sports, but it is not a single physical component but is composed of elements of balance, coordination, speed, reflexes, strength, endurance, and stamina. The agility of an athlete in changing body movements is an essential component in team or team sports such as futsal and soccer. Because during the game, players perform movements such as running and changing the direction of movement quickly, both in dribbling and blocking the enemy's movement (Milanovic et al., 2011). Agility or agility is an essential quality in many sports played on the field.

In addition to strength, agility also plays an essential role in every sports activity. Therefore agility needs to be improved so that achievement can be maximized. Agility is the ability to change the direction of the body efficiently and effectively. Achieving this requires a combination of several other biomotor components: static and dynamic balance, speed, strength, and coordination. Agility or agility is very dominant in sports whose characteristics require high movement speed and the ability to change direction suddenly according to the situation at hand and desired (Sheppard and Young, 2007). An athlete's agility can be adequately possessed if supported by other biomotor abilities such as speed, reaction speed, strength, balance, and movement skills. 
According to Ismayati (2008: 41), judging from the role and involvement in various kinds of activities, agility can be grouped, namely: a) general agility, meaning that activities are carried out closely with routine daily activities and sports in general, b) agility in particular, it means the agility that is needed in certain sports. The agility required has specific characteristics and characteristics according to the demands and expectations of the sport being trained. Of course, this is positively correlated and has advantages; among others, complex movements will be easier to do, less prone to injury, and support techniques in exercise. Based on some of the opinions above, it can be concluded that agility is the ability to change the direction of movement and body position quickly and precisely without losing balance and body awareness. The agility component cannot stand alone; many other features and factors cause a person to have agility or not. The agility test in this study used the Side Step Test.

There are various forms of exercise to improve physical condition, one of which is plyometric training which has been shown to enhance explosive power performance in many sports. This exercise combines strength with the speed of movement to produce power. Various studies in sports science, with the scope of exercise models for physical improvement, have been widely carried out, of course with different results in each study; generally, the difference in each study apart from the characteristics of the people trying is the manipulation of the exercise variable. Manipulation of exercise variables is very dependent on the purpose of the exercise, is individual, and adapts to the activities that are usually carried out by the person (ACSM, 2002).

The Bounding Exercise Program (BEP) is another potentially effective training program performed after a warm-up. It consists of a series of leg jump exercises characterized by stretching-muscle shortening or an eccentric mobile phase, an amortization phase, and a concentric shortening phase. This stretch-shortening cycle strengthens the elastic properties of muscle tissue connectives, thereby increasing muscle strength (during eccentric and concentric contractions) by allowing muscles to accumulate during the pre-stretch/eccentric phase and energy release or concentric phase (S. Van de Hoef, 2017).

Bounding Exercise Program (BEP) is an exercise that prioritizes jumping, in the literature, the Bounding Exercise Program (BEP) is referred to as a bound exercise this is because the movement is a unit of a series of jumps, the Bounding Exercise Program (BEP) can also be categorized as a plyometric exercise. This plyometric exercise contains three phases, namely the eccentric phase, the amortization phase (the time between the eccentric and concentric contractions), and the concentric shortening phase (Davies G, 2015).

The research that will be carried out in this dissertation is in Bounding Exercise Program (BEP) exercises to increase physical agility and leg muscle strength. The choice of the single leg and double leg Bounding Exercise Program (BEP) exercise method is because these two methods are the same type of bounding exercise but have different implementations so that scientific answers will be known about giving this treatment.

This study was designed to develop the results of previous research. As in the prior research, S. Van de Hoef (2017) with the title "The preventive effect of the bounding exercise program on hamstring injuries in amateur soccer players: the design of a randomized controlled trial." This study discusses the Bounding Exercise Program (BEP) exercise for injury recovery, but there is no data on the physical improvement of the leg muscles in this study. 
The equation of previous research with current research is that previous research by $\mathrm{S}$. Van de Hoef (2017) used the Bounding Exercise Program (BEP) exercise method. The sample used in this study was limited to male students of the 2017 Physical Education Study Program STKIP PGRI Jombang. The results of this study are expected to provide recommendations regarding the most effective exercise program to improve leg muscle performance through the Bounding Exercise Program (BEP) exercise method for the formation of physical conditions in general.

\section{Research Methods}

The type of research method in this study is a quantitative method, namely a research method based on the philosophy of positivism (relatively fixed, concrete, observable, measurable, and the relationship of symptoms is causal). The collecting data using research instruments, data analysis is quantitative/statistical, intending to test the established hypothesis (Sugiyono, 2016: p8).

In this study, the treatments given to male students of the 2017 Physical Education Study Program STKIP PGRI Jombang were (1) bounding exercise program single leg and (2) bounding exercise program double leg. This study aims to determine the effect of the Bounding Exercise Program (BEP) on increasing physical strength and agility. Based on this, this research belongs to the type of quasi-experimental research.

In this regard, Wilhelm Wundt in Alsa (2004) suggests the conditions that must be met by researchers in carrying out experimental research, namely: (1) researchers must be able to determine when and where they will conduct research intentionally; (2) research on the same thing must be repeated under the same conditions; (3) the researcher must be able to manipulate (change, control) the variables studied according to what he wants; (4) a comparison group (control group) is needed other than the group being treated (experimental group).

\section{Discussion}

The dependent variables in this study include leg muscle strength and agility. Data analysis was performed on the pre-test, post-test, and delta data (difference between post-pre). The study results will be discussed regarding the independent variables, which include single leg bounding exercise and double leg bounding exercise carried out in each group and the dependent variable.

Then the strength measurement test results with the number of samples $n=42$ were carried out before and after treatment (Single-Leg Bounding and Double Leg Bounding). The description of the results of the average and standard deviation (SD) data can be seen in the table as follows:

Table 1. Description of Strength test results (kilograms)

\begin{tabular}{lll}
\hline Variable & \multicolumn{2}{l}{ Average $\pm \mathrm{SD}(\mathrm{Kg})$} \\
\cline { 2 - 3 } & Single-Leg Bounding & Double Leg Bounding \\
\hline Pre-test & $145,89 \pm 19,41$ & $148,18 \pm 32,02$ \\
Post-test & $182,43 \pm 24,60$ & $166,71 \pm 31,96$ \\
\hline
\end{tabular}


The table's description of the strength measurement data results shows the pre-test results in the Single-Leg Bounding group of $145.89 \pm 19.41 \mathrm{Kg}$, the Double Leg Bounding group of $148.18 \pm 32.02 \mathrm{Kg}$. Then after the treatment (exercise), a post-test was performed, and the results showed an increase in the Single-Leg Bounding group of $182.43 \pm 24.60 \mathrm{Kg}$, the Double Leg Bounding group $166.71 \pm 31.96 \mathrm{Kg}$. For more details, a description of the power variable is presented in the following figure.

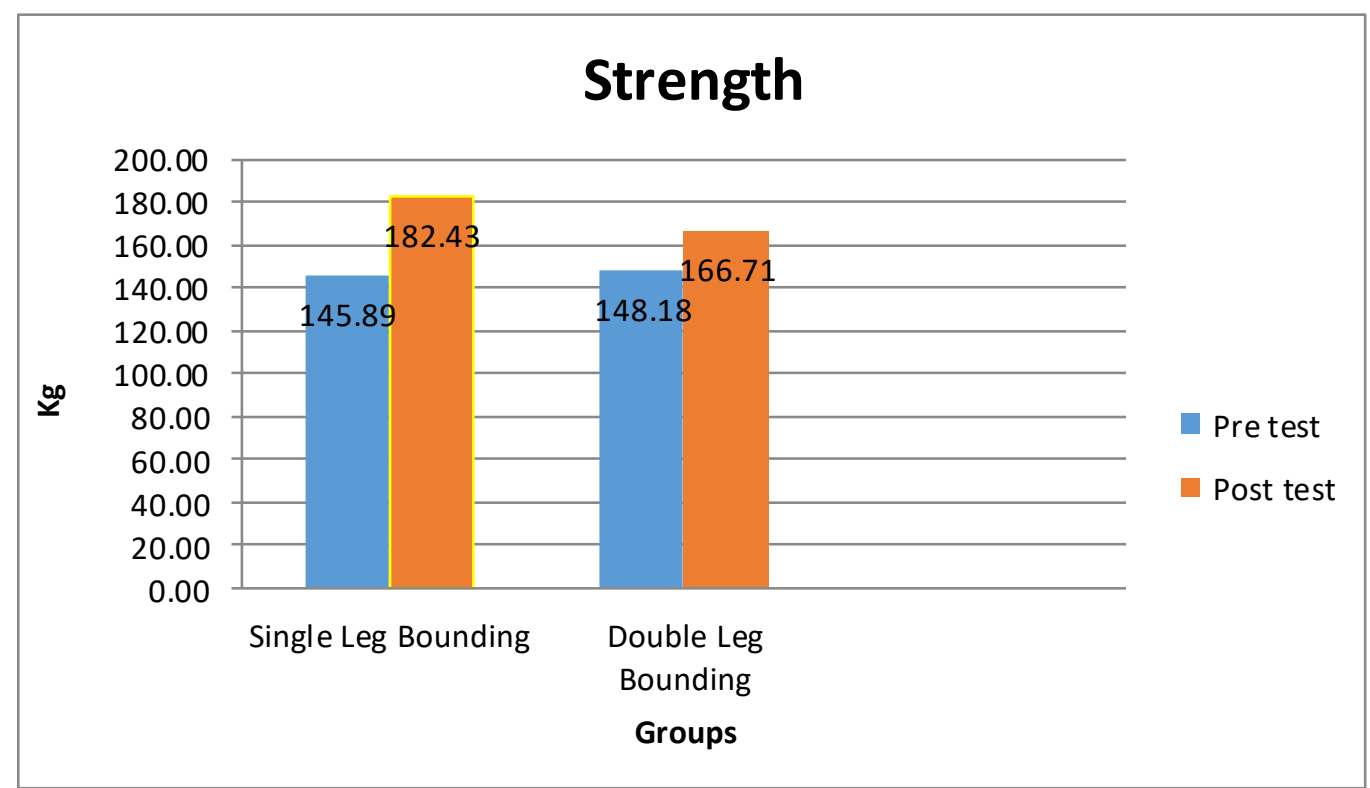

Figure 1. Average strength before and after treatment in the Single-Leg Bounding and Double Leg Bounding groups for the strength group

Table 2. Description of Agility test results (times)

\begin{tabular}{lll}
\hline Variable & \multicolumn{2}{l}{ Average \pm SD (times) } \\
\cline { 2 - 3 } & Single-Leg Bounding & Double Leg Bounding \\
\hline Pre-test & $28,93 \pm 6,04$ & $29,07 \pm 4,29$ \\
Post-test & $33,93 \pm 5,69$ & $31,43 \pm 4,52$ \\
\hline
\end{tabular}

The table's description of the strength measurement data results shows the pre-test results in the Single-Leg Bounding group of $28.93 \pm 6.04$ Times, the Double Leg Bounding group of $29.07 \pm 4.29$ Times. Then after the treatment (exercise), a post-test was carried out, and the results obtained increased in the Single-Leg Bounding group by $33.93 \pm 5.69$ times, the Double Leg Bounding group by $31.43 \pm 4.52$ times. For more details, a description of the agility variable is presented in the following figure. 


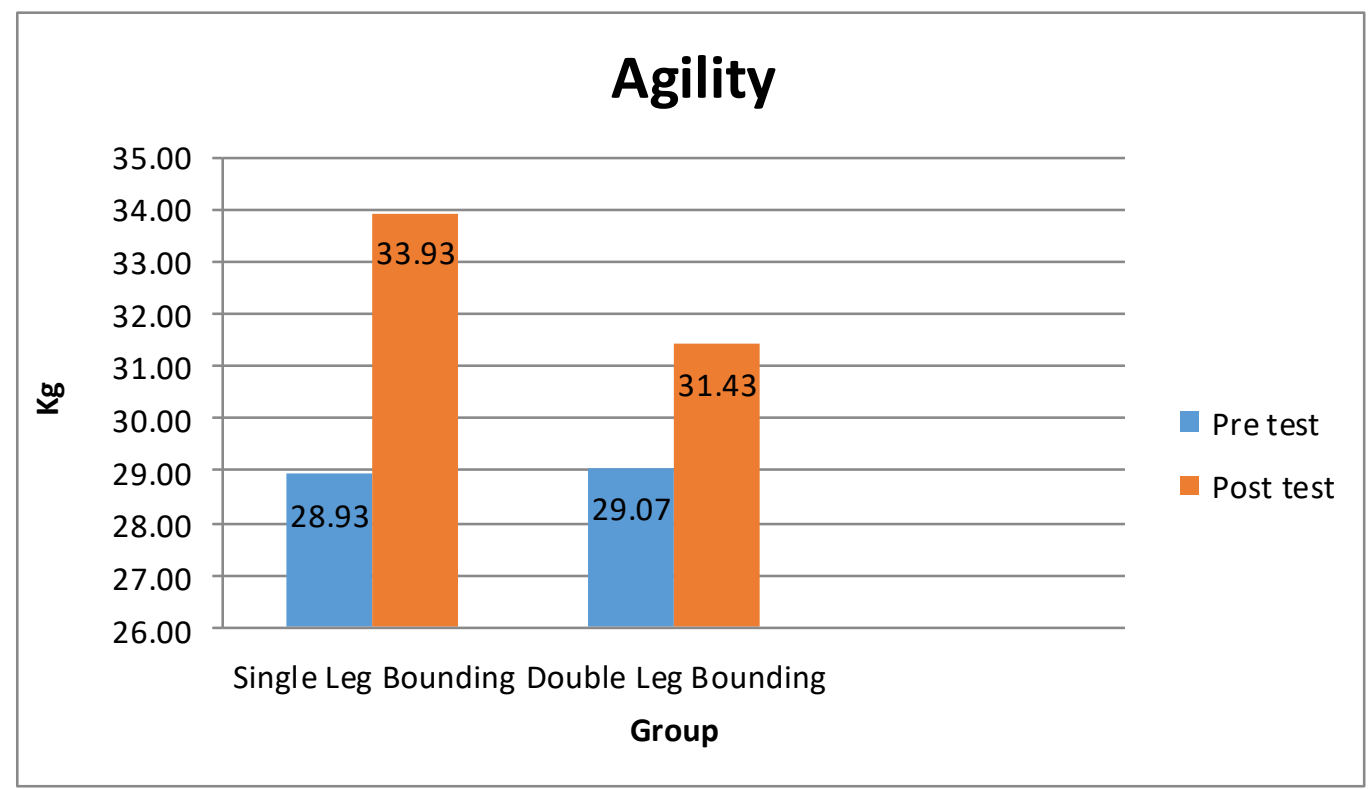

Figure 2. Average strength before and after treatment in the Single-Leg Bounding and Double Leg Bounding groups for the agility group

\subsection{Post Hoc Test}

After the Manova test was carried out, a post hoc test was carried out using the LSD test on the strength and agility variables. The Post Hoc test will discuss the differences between the dependent variables, namely leg muscle strength and agility, based on the independent variables, namely the Single-leg bounding exercise method and the Double leg bounding exercise. If the data is homogeneously distributed, then the post hoc test uses Bonferroni. And if the data is heterogeneous, then the post hoc test uses Games Howell.

The basis for decision-making is as follows.

a. Probability of error $=0.05$

b. Ho is accepted; if the significance value is 0.05 , there is no significant difference between one exercise and another.

c. Ho is rejected; if the significance value is 0.05 , there is a significant difference between one exercise and another.

The results of the post hoc test can be seen in the following table.

Table 3. Calculation Results of the Advanced Test (Post Hoc Test)

\begin{tabular}{|l|cl|c|c|}
\hline \multicolumn{5}{|c|}{ Multiple Comparisons } \\
\hline \multirow{2}{*}{ Dependent Variable } & $(\mathrm{I})$ & \multicolumn{1}{c|}{ (J) } & $\begin{array}{c}\text { Mean Difference } \\
\text { (I-J) }\end{array}$ & Sig, \\
\hline \multirow{2}{*}{ Leg muscle strength } & Single Leg & Double Leg & $*$ &, 001 \\
\cline { 2 - 5 } & Double Leg & Single Leg & $*$ &, 001 \\
\hline \multirow{2}{*}{ Agility } & Single Leg & Double Leg & $*$ &, 000 \\
\cline { 2 - 5 } & Double Leg & Single Leg & $*$ &, 000 \\
\hline
\end{tabular}

Based on the table above, the sig value indicates the physical components that have significant differences. $<0.05$ or has a sign $\left(^{*}\right)$. So that the Manova test can be concluded as follows: 
The single-leg bounding exercise method with double leg bounding has a significant difference in the variable leg muscle strength with single leg bounding $>$ double-leg bounding so that the single-leg bounding exercise gives a more meaningful effect than the double leg bounding exercise.

The single-leg bounding exercise method with double leg bounding significantly differs in the agility variable with single leg bounding $>$ double-leg bounding so that the single-leg bounding exercise gives a more meaningful effect than the double leg bounding exercise.

\section{Conclusion}

The conclusions in this study are as follows:

1. There is a significant effect of using Single leg bounding exercise on increasing physical performance, strength, and agility.

2. There is a significant effect of using Double leg bounding exercise on increasing physical performance, strength, and agility.

3. There is a significant difference in the form of Single leg bounding and Double leg bounding exercises to increase strength, agility, and the most effective form of exercise in increasing the ability of leg muscle strength and agility by using single leg bounding exercises.

Based on the results of research that has been done, it is recommended as follows:

1. To keep the exercise intensity high, the heart rate is maintained by using a pulse detector or heart rate monitor.

2. Further research is needed physiologically regarding the effect of different training methods on the bounding method; this method is still common in selecting other plyometric exercises such as countermovement jumps, depth jumps, and others which are still the primary choice of trainers and researchers.

3. Single leg bounding and Double leg bounding exercises can increase physical performance, balance strength, agility, and leg power. This method can be used by achievement sports requiring biomotor abilities, such as soccer, volleyball, basketball, and others requiring lower extremity biomotor abilities.

The discussion of these findings describes the problems and results that emerged during research on the relationship between bilateral training and unilateral training with the plyometric Bounding Exercise Program (BEP) method to improve agility, strength, balance, and leg muscle power. The researcher used a research sample of male sports students with the criteria of having the same age range and having an ideal body mass index. This sample selection is because the research to be carried out requires samples with a reasonable lower extremity physical basis. Because we all know that plyometric training is a strenuous exercise using body weight as a burden when carrying out movements, so for this reason and the selection of samples that have an ideal body mass index, researchers have tried to minimize the risk of injury during the study. The problems that arise are in the form of shortcomings from this study which were still not perfect at the research time. However, on the other hand, this research finds useful new things to improve previous research. The following are some of the findings formulated by the researchers as follows: 
An overview of the results of research that researchers have carried out; some of them are trying to get scientific evidence on the use of bilateral training and unilateral training methods with the plyometric Bounding Exercise Program (BEP) method to improve agility, strength, balance, and leg muscle power. The results of this study are that there is a significant relationship between the plyometric Bounding Exercise Program (BEP) training method, either using the one-leg or unilateral training method, and the use of two legs or commonly called bilateral training to improve agility, strength, balance, and muscle power limbs. As for the previous research, S. Van de Hoef (2017) with the title "The preventive effect of the bounding exercise program on hamstring injuries in amateur soccer players: the design of a randomized controlled trial." This study discusses the Bounding Exercise Program (BEP) exercise for injury recovery; the researchers tried to develop this research by using the Bounding Exercise Program (BEP) exercise method to improve the physical abilities of the lower extremities, especially the ability of the legs.

Science and technology are growing; it also has an impact on the world of modern sports. Many coaches or sports experts are trying to make a particular training method for achievement athletes to increase and bring out prime physical potential during championships or matches. Therefore, researchers feel that this research still needs to be developed to get more perfect results. For example, they used a sample of female athletes, athletes in other sports, or other physical abilities needed to achieve excellent physical abilities.

The results of the research that have been carried out and with data analysis can be seen the results that there is a significant relationship between the plyometric Bounding Exercise Program (BEP) training method using the one leg or unilateral training method and the use of two legs or commonly called bilateral training to increase agility abilities, strength, balance, and leg muscle power.

\section{References}

Acep Rusmawan. (2010). The Effect of Several Kinds of Exercise Methods on Increasing Muscle Strength. http://file.upi.edu/Derektori/Jurnal/Pendidikan_Dasar/Nomor_14-Oktober_2010.

ACSM (2002). Exercise Management For Persons With Chronic Diseases And Disabilities. 2nd edition. human kinetics

Aghababaei Z (2010). A Comparative Study Of the Effects Of the Selected Plyometric, Weight resistance and Plyometric weight resistance Training Methods On Leg explosive power, Lower extremity muscular Strength and Agility Of Trained Females. Rasht: Guilan University;(2010).

Davies G, Riemann BL, Manske R (2015). Current concepts of plyometric exercises. Int J Sports Phys Ther. 2015;10(6):760-86.

Hasibuan, S. W., et al. (2019). The Effect of Health and Religious Beliefs on Consumer Consciousness of Using Halal Cosmetics. Budapest International Research and Critics Institute-Journal (BIRCI-Journal) Volume 2, No 3, Page: 239-249.

Ismayarti. (2008). Sports Tests \& Measurements. Surakarta: Universitas Sebelas Maret Surakarta.

Novita, W., et al. (2020). The Relationship between Geography Access and Utilization of Basic Emergency Neonatal Obstetric Services (PONED) in Hamparan Perak Health Center, Deli Serdang Regency in 2018. Budapest International Research and Critics Institute-Journal (BIRCI-Journal) Volume 3, No 1, Page: 674-681. 
S. Van de Hoef., B. M. A., Huisstede., M. S., Brink., N. de Vries., E. A., Goedhart., F. J. G., Backx., (2017). The preventive effect of the bounding exercise program on hamstring injuries in amateur soccer players: the design of a randomized controlled trial. Department of Rehabilitation, Physical Therapy Science and Sports, Rudolf Magnus Institute of Neurosciences, University Medical Center Utrecht, Utrecht, The Netherlands

Sugiyono, (2016). Quantitative, Qualitative, and R\&D Research Methods. Bandung: PT Alfabet. 